\title{
Effect of supplementation with ferrous sulfate or iron bis-glycinate chelate on ferritin concentration in Mexican schoolchildren: a randomized controlled trial
}

Ximena Duque ${ }^{1}$, Homero Martinez ${ }^{2,3^{*}}$, Jenny Vilchis-Gil ${ }^{3}$, Eugenia Mendoza', Sergio Flores-Hernández ${ }^{4}$, Segundo Morán', Fabiola Navarro ${ }^{1}$, Victoria Roque-Evangelista', Anayeli Serrano ${ }^{1}$ and Robertino M Mera ${ }^{5}$

\begin{abstract}
Background: Iron deficiency is one of the most common nutritional deficiencies worldwide. It is more prevalent when iron requirements are increased during pregnancy and during growth spurts of infancy and adolescence. The last stage in the process of iron depletion is characterized by a decrease in hemoglobin concentration, resulting in iron deficiency anemia. Iron deficiency, even before it is clinically identified as anemia, compromises the immune response, physical capacity for work, and intellectual functions such as attention level. Therefore, interventions addressing iron deficiency should be based on prevention rather than on treatment of anemia. The aim of this study was to compare short- and medium-term effects on ferritin concentration of daily supplementation with ferrous sulfate or iron bis-glycinate chelate in schoolchildren with iron deficiency but without anemia.

Methods: Two hundred schoolchildren from public boarding schools in Mexico City who had low iron stores as assessed by serum ferritin concentration but without anemia were randomly assigned to a daily supplement of $30 \mathrm{mg} /$ day of elemental iron as ferrous sulfate or iron bis-glycinate chelate for 12 weeks. Iron status was evaluated at baseline, one week post-supplementation (short term), and 6 months (medium term) after supplementation.

Results: Ferritin concentration increased significantly between baseline and post-supplementation as well as between baseline and 6 months after supplementation. One week post-supplementation no difference was found in ferritin concentration between iron compounds, but 6 months after supplementation ferritin concentration was higher in the group that received bis-glycinate chelate iron. However, there is no difference in the odds for low iron storage between 6 months after supplementation versus the odds after supplementation; nor were these odds different by type of supplement. Hemoglobin concentration did not change significantly in either group after supplementation.
\end{abstract}

Conclusions: Supplementing with $30 \mathrm{mg} / \mathrm{d}$ of elementary iron, either as ferrous sulfate or iron bis-glycinate chelate for 90 days, showed positive effects on increasing ferritin concentration in schoolchildren with low iron stores, and this effect persisted 6 months after supplementation.

Keywords: Iron deficiency, Serum ferritin, Ferrous sulfate, Bis-glycinate chelate iron, Schoolchildren

\footnotetext{
* Correspondence: homero@rand.org

${ }^{2}$ RAND Corporation, Santa Monica, California 90407, USA

${ }^{3}$ Hospital Infantil de México Federico Gómez, Dr. Marquez No. 162, CP 06720

México, DF, México

Full list of author information is available at the end of the article
} 


\section{Background}

Iron deficiency is one of the most common nutritional deficiencies worldwide. It is more common when iron requirements are increased due to the growth spurts of infancy and adolescence, as well as during pregnancy, when the fetus derives all its iron stores from the mother. The last stage in the process of iron depletion is characterized by a decrease in hemoglobin concentration, resulting in iron deficiency anemia [1,2]. Anemia is the result of a negative iron balance that may be due to any or a combination of the following causes: inadequate iron intake, impaired or low iron absorption, poor iron utilization, or increased iron losses, such as chronic blood loss. In addition to iron deficiency, mineral and vitamin insufficiencies (e.g., folate, vitamin B12, and vitamin A), chronic inflammation, parasite infestation, and hemoglobin $(\mathrm{Hb})$, hereditary disorders can also cause anemia $[1,3,4]$.

Iron homeostasis results from a complex set of events that start by absorption of iron by the intestinal cells, its transport into the cell, and its further release into the blood stream, where it is transported by means of carrier proteins (i.e., transferrin), stored in different body stores, mainly bone marrow, liver, and spleen-known as ferritin complexes-and eventually used in red cell formation by bone marrow. Therefore, different hematological markers-the most common of which include ferritin, serum transferrin, serum transferrin receptors, total serum iron, number and morphology of red blood cells, and $\mathrm{Hb}$ concentration-may be used to assess iron status. Given that $\mathrm{Hb}$ depletion represents the last stage in iron deficiency, $\mathrm{Hb}$ concentration is widely used to diagnose anemia, while serum ferritin is commonly used as indicator of iron status in populations $[1,5]$.

Iron deficiency, even before clinically identified as anemia, compromises the immune response, physical capacity for work, and intellectual functions such as attention level. This is why children are particularly vulnerable to iron deficiency and/or anemia, as they are in a stage of rapid growth. Therefore, interventions addressing iron deficiency should be based on prevention rather than on treatment of anemia [6-8].

The bioavailability and iron absorption from the daily diet are influenced by the type and quantity of iron present in food as well as by the presence of inhibitors and promoters of iron absorption in the diet and the individual's iron status [8]. It has been estimated that onefifth of the population worldwide has an iron-deficient diet and that $46 \%$ of children between 5 and 14 years are anemic $[1,2,9]$. The majority of these children live in developing countries. In addition, $56 \%$ of pregnant women in developing countries are anemic. Although the precise estimate of what percentage of anemia is due to iron deficiency, parasitical infections or other deficiencies in vitamins, minerals, or nutritious food is not known; it is estimated that $50 \%$ of anemia is due to iron deficiency $[1,2,9]$.

According to the 2006 National Health and Nutrition Survey in Mexico (relevant to the time in which the study was conducted), the prevalence of low iron stores in 5-11-year-old children nationwide was $13 \%$ [10]. In Mexico City, the prevalence of iron deficiency in children $5-11$ years old was $4.5 \%$, with a $95 \%$ confidence interval $(95 \% \mathrm{CI})$ between 2.3 and 8.6, and $11 \%$ (95\% CI: $7.4-14.5)$ in adolescents $12-14$ years old [11]. The prevalence of anemia according to the 2012 National Health and Nutrition Survey in Mexico was 10.1\% (95\% CI: 9.3 - 10.9) in children 5-11 years old [12]. In school-aged children, the World Health Organization recommends doses of $30 \mathrm{mg} /$ day of iron and $250 \mathrm{mg} /$ day of folic acid for 3 months to prevent iron deficiency anemia $[1,8]$. In age $0-13$ years, the upper tolerable limit recommended by the Institute of Medicine in the United States is $40 \mathrm{mg}$ of elemental iron per day [13]. A recent Cochrane systematic review of iron supplementation in children addressed the effects of intermittent oral iron supplementation versus no supplementation (placebo) in children under 12 years of age found that iron supplementation improves hematological outcomes. The risk ratio (RR) of presenting anemia was 0.51 (95\% CI: 0.37 0.72 ), while the $R R$ of presenting iron deficiency was 0.24 (95\% CI: $0.06-0.91$ ), and iron status assess by serum ferritin showed higher mean levels for those receiving supplements compared to those receiving no treatment [1]. It should be noted, however, that most of the 33 studies included in this review were conducted in settings with a high prevalence of anemia.

Despite the wide range of pharmaceutical products available to treat anemia, there have been few studies about school-age children concerning the effect of preventive supplementation on nutritional iron status. Further, few studies have compared the relative effectiveness of different iron compounds. Ferrous sulfate is the most commonly used iron compound in supplementation programs because of its efficiency and low cost $[1,14,15]$. Iron bis-glycinate chelate has been proposed as an alternative to ferrous sulfate because of its increased bioavailability. Due to its chemical composition, with a ferrous cation coupled to two glycine molecules, it does not form insoluble compounds with substances like phytates, oxalates, and tannins present in high quantity in cerealbased diets, which have a high content of iron absorption inhibitors [16-19]. Furthermore, this type of iron has caused less collateral effects with high doses of $60 \mathrm{mg} / \mathrm{d}$ or more of elementary iron [20]. Therefore, in equal doses, iron bis-glycinate chelate would be expected to have a larger effect on body iron status compared to ferrous sulfate [19,21-23]. However, most of the studies 
using this form of iron relate to food enrichment interventions [19,21-23].

Given that iron supplementation studies have clearly shown positive effects on treatment of anemia $[1,8,9,14,15]$, it is important to increase our knowledge on the prevention of iron deficiency anemia. The objective of this study was to compare the effect on serum ferritin concentration of daily supplementation with $30 \mathrm{mg}$ of elemental iron as ferrous sulfate versus iron bis-glycinate chelate in schoolchildren with iron deficiency but without anemia.

\section{Methods}

A randomized, double-blind clinical trial was conducted between June 2005 and March 2008, enrolling children aged 5-13 years old from three elementary schools in Mexico City. This study was carried out with children from low-income families. All of them attended public boarding schools where the children remain five days per week and go home on weekends and vacations. Diets in participating boarding schools are very similar, as the menus and food delivered are run from a central facility and standardized across participating schools.

A sample size was calculated following the rationale for a bioequivalence study [24]. Based on previous information, the probability of success with the administration of iron sulfate was calculated as 0.81 ; while success with iron bis-glycinate was calculated as 0.86 , we set the maximum allowable difference at no more than 0.1. The calculated sample size rendered 75 children per group, to which we added an additional $20 \%$ for possible attrition, for a final sample size of 90 children per group.

$\mathrm{Hb}$ and ferritin concentrations were measured to screen for potential participants. Children with normal hemoglobin concentration but with ferritin lower than the cut-off were considered to have low iron stores but no anemia and were included in the study. The following cut-offs were applied: serum ferritin $<12 \mu \mathrm{g} / \mathrm{l}$ and $\mathrm{Hb}$ adjusted for altitude $\geq 120 \mathrm{~g} / \mathrm{l}$ for children 12 years or older and $\geq 115 \mathrm{~g} / \mathrm{l}$ for children less than 12 years $[8,25]$. Children with $\mathrm{Hb}$ and ferritin lower than the specified cutoff were considered as having iron deficiency anemia; they received treatment with the standard oral iron treatment but were not included in the study.

\section{Study intervention}

Children with iron deficiency without anemia were randomly assigned to daily supplements with ferrous sulfate or bis-glycinate chelate iron (30 mg of elemental iron plus $100 \mu \mathrm{g}$ of folic acid) for 90 days. Computer-generated random numbers (http://www.randomization.com) were used to assign each child with iron deficiency to either supplementation group. Supplement pills were identical in size, form, and color, and were coded to preserve blinded assignment. Supplementation was administered Monday through Friday by trained project staff. The person responsible for administering the supplement kept a schedule and a registry of which child received the supplement, according to the random assignment. Compliance was assessed by means of the daily registration of supplement administration at school, according to the schedule kept by project staff responsible for its administration. For non-school days (i.e., weekends, holidays, or days with no school attendance), parents were in charge of keeping the schedule and writing down information about the assigned supplement pill's administration. This same schedule included questions related to potential side effects. All participants received a single $400 \mathrm{mg}$ albendazol dose at the beginning of the study as anti-helminthic prophylaxis.

\section{Biochemical determinations}

A venous blood sample was taken by skilled personnel on three occasions to determine serum ferritin and $\mathrm{Hb}$ concentrations. The samples were taken at baseline, a week after completing iron supplementation, and 6 months after treatment completion (6 months post-treatment). The sample was taken only if the child did not have a cold or gastrointestinal infection symptoms (pain, temperature, cough, vomiting, or diarrhea) the week before. If symptoms had been present, blood samples were taken at a later date. Blood cytology samples were analyzed by cellular counter (Beckman Coulter, Fullerton, CA). Ferritin was determined by immune-radiometric assay (Inmunotech SA, Marseille, France).

\section{Anthropometry and diet}

All participants were weighed and measured using standard procedures as suggested by Lohman [26]. Body mass index (weight in $\mathrm{kg} /$ height in $\mathrm{m}^{2}$ ) was calculated and children were categorized by age and gender as having normal weight, being overweight, or being obese [27]. The height-for-age $z$ score was calculated and children were classified as showing normal nutritional status $(z$ score $\geq-1)$ or a slight-to-moderate malnutrition status $(z$ score $<-1)$ [28].

Semi-quantitative 24-hour recall questionnaires were used to evaluate the children's nutrient intake. Standard portions of the different foods offered at school were weighed and the ingredients and quantities were recorded. Each child was asked how much food he or she had eaten using a 3-option scale: everything, nothing, or about half of what was served. Any food eaten by the children other than what was offered in school was recorded. The Mexican Table for Food Equivalence and the Mexican Food Composition Table [29,30] were used to calculate the energy and nutrient (protein, carbohydrate, lipids, iron, and vitamins) intake. 


\section{Sociodemographic characteristics}

Sociodemographic information including age, gender, number of occupants in the dwelling, and parents' education and occupation was collected through a questionnaire given to schoolchildren's parents or tutors.

\section{Ethical approval}

This study was conducted according to the guidelines of the Declaration of Helsinki and was approved by the Research and Ethics Committees of the Mexican Institute of Social Security in Mexico City. Written consent was obtained from the participants' parents or tutors, and written assent was requested from children older than 7 years.

\section{Statistical analysis}

Descriptive statistics were used to describe the baseline status of the study population. Variables related to iron nutritional status, $\mathrm{Hb}$, and ferritin concentration were analyzed using continuous and categorical scales.

The effect of supplementation was evaluated within and between groups, one week after supplementation and 6 months after supplementation. Student's $t$-test was used to evaluate the difference in $\mathrm{Hb}$ and ferritin concentration between groups. Pearson's $X^{2}$ test was used to analyze changes in the classification of nutritional iron status between groups.

Multivariate analyses to evaluate effects of supplementation on hemoglobin and ferritin concentration during the study with the two iron compounds were carried out using mixed-effects linear regression models. The models were adjusted for fix variable gender and for age as a variable time dependent. Possible interaction between the iron compound and the time of assessment of the outcome variables $\mathrm{Hb}$ and ferritin concentration were evaluated. As time of assessment and iron compound interaction was statistical significance in the model to ferritin concentration, the mean of ferritin by iron compound and study stage was described using margins analyses [31].

Mixed-effects logistic regression model was used to evaluate the risk of having iron deficiency after supplementation by iron supplementation group adjusting by age, sex, ferritin, and hemoglobin concentration at baseline.

Values of $p<0.05$ were considered statistically significant. All data analyses were carried out using Stata 12 SE (Stata Corp., College Station, TX).

\section{Results}

A total of 1,020 children were screened, and 200 (19.6\%) who showed low iron stores without anemia were included in this study. Children were randomly allocated to two treatment groups: 101 children received iron bisglycinate chelate and 99 children received ferrous sulfate.

A total of 176 children (88\%) who received iron supplementation were available for the one-week post- supplementation assessment of iron status. There were missing values for $14.9 \%$ of children who received iron bis-glycinate chelate, and $9.1 \%$ for children who received ferrous sulfate. Six months after supplementation, there were samples available for 89 children $(44.5 \%$ of the total intervention population). Losses to follow-up at 6 months after supplementation were $55.4 \%$ for the group supplemented with bis-glycinate chelate and $55.6 \%$ for the group supplemented with ferrous sulfate (Figure 1). There were no statistically significant differences between the baseline characteristics of children who completed the study and those who were lost to follow-up, except that children who had missing values 6 months after supplementation were older than children who completed the study. The age difference was statistically significant for the iron bis-glycinate chelate group $(8.7 \pm 1.9$ vs. $9.7 \pm 2.1$, $p=0.018$ ). Fear and unpleasantness related to taking blood samples were the most common reasons for children not to complete the study.

There were no cases in which supplementation had to be discontinued due to undesirable side effects or gastrointestinal discomfort. Twenty-two children (10.4\%) had one of the following side effects for one or more days: diarrhea $(n=3)$, abdominal pain $(n=15)$, nausea $(n=9)$, constipation $(n=2)$, or metallic taste $(n=11)$. There were no significant differences between the groups in the presentation of side effects potentially associated to iron supplementation.

The mean energy intake, after adjusting for age and sex, was $9188 \pm 468 \mathrm{KJ} / \mathrm{d}$. The calorie distribution value of macronutrient intake was $15.3 \%$ from proteins, $56.3 \%$ from carbohydrates, and $27.8 \%$ from lipids, and the mean iron consumption was $11.7 \pm 0.7 \mathrm{mg} / \mathrm{d}$. There were no significant differences in the mean intake of micronutrients or iron between supplemented groups.

\section{Study population characteristics}

The mean age of children with low iron stores was $9.3 \pm$ 1.9 years. The mean of ferritin was $8.7 \pm 2.1 \mu \mathrm{g} / \mathrm{l}$. The mean of $\mathrm{Hb}$ was $140 \pm 9.1 \mathrm{~g} / \mathrm{l}$. There were no significant statistical differences in the sociodemographic or nutritional characteristics between supplementation groups (Table 1).

\section{Descriptive results: serum ferritin and hemoglobin concentration}

During the follow-up, there was a statistically significant positive effect of supplementation on ferritin concentration and on the classification of iron status. At baseline, all schoolchildren had low iron storages as evaluated by ferritin concentration; one week after supplementation and 6 months post-supplementation, only $10 \%$ of children had low iron storages (Table 2). 




Figure 1 Study population. Flow of participants through the trial.

Table 1 Characteristics of study population according to supplementation group

\begin{tabular}{|c|c|c|c|c|c|c|c|}
\hline \multirow[t]{2}{*}{ Characteristics/Supplement compound } & \multicolumn{2}{|c|}{$\begin{array}{c}\text { All } \\
N=200\end{array}$} & \multicolumn{2}{|c|}{$\begin{array}{l}\text { Bis-glycinate chelate iron } \\
n=101\end{array}$} & \multicolumn{2}{|c|}{$\begin{array}{c}\text { Ferrous sulfate } \\
n=99\end{array}$} & \multirow[t]{2}{*}{$P$ value ${ }^{\mathrm{a}}$} \\
\hline & $n$ & $\%$ & $n$ & $\%$ & $n$ & $\%$ & \\
\hline \multicolumn{8}{|l|}{ Sex } \\
\hline Male & 91 & 45.5 & 42 & 41.6 & 49 & 49.5 & \\
\hline Female & 109 & 54.5 & 59 & 58.4 & 50 & 50.5 & 0.261 \\
\hline Age $(\text { years })^{b}$ & 9.3 & 1.9 & 9.3 & 2.1 & 9.4 & 1.7 & 0.728 \\
\hline \multicolumn{8}{|l|}{ Height for age ${ }^{c}$} \\
\hline Normal & 136 & 69.1 & 72 & 72.7 & 64 & 66.0 & \\
\hline Low or moderate malnutrition & 60 & 30.6 & 27 & 27.3 & 33 & 34.0 & 0.305 \\
\hline \multicolumn{8}{|l|}{ Body mass index ${ }^{d}$} \\
\hline Normal & 147 & 73.0 & 70 & 70.7 & 73 & 75.3 & \\
\hline Overweight or obese & 53 & 27.0 & 29 & 29.3 & 24 & 24.7 & 0.473 \\
\hline \multicolumn{8}{|l|}{ Mother's schooling } \\
\hline High school or more & 60 & 32.3 & 30 & 31.9 & 30 & 32.6 & \\
\hline Middle school or less & 126 & 67.7 & 64 & 68.1 & 62 & 67.4 & 0.919 \\
\hline Hemoglobin concentration $\left(\mathrm{g} / \mathrm{l}^{\mathrm{b}}\right.$ & 140.9 & 9.1 & 141.6 & 10.3 & 140.2 & 7.6 & 0.273 \\
\hline Ferritin concentration $\left(\mu \mathrm{g} / \mathrm{l}^{\mathrm{b}}\right.$ & 8.7 & 2.1 & 8.7 & 2.1 & 8.9 & 2.1 & 0.548 \\
\hline
\end{tabular}

${ }^{\mathrm{a}}$ Pearson's $X^{2}$ test.

${ }^{\mathrm{b}}$ Mean and standard deviation. Student's $t$ test.

'WHO's reference population, 2007 [28].

${ }^{\mathrm{d}}$ Cole et al. Cut-off point by age and sex [27]. 
Table 2 Comparison of nutritional iron status at baseline and during the follow-up by iron compound supplement

\begin{tabular}{|c|c|c|c|c|c|c|c|c|c|c|c|c|c|c|c|}
\hline \multirow[b]{2}{*}{ Iron Status/Supplement compound } & \multicolumn{5}{|c|}{ Baseline } & \multicolumn{5}{|c|}{ Post-supplementation } & \multicolumn{5}{|c|}{6 months after supplementation } \\
\hline & \multicolumn{2}{|c|}{$\begin{array}{l}\text { Bis-glycinate } \\
\text { chelate } \\
n=101\end{array}$} & \multicolumn{2}{|c|}{$\begin{array}{l}\text { Ferrous } \\
\text { sulfate } \\
n=99\end{array}$} & $P$ value & \multicolumn{2}{|c|}{$\begin{array}{l}\text { Bis-glycinate } \\
\text { chelate } \\
n=86\end{array}$} & \multicolumn{2}{|c|}{$\begin{array}{l}\text { Ferrous } \\
\text { sulfate } \\
n=90\end{array}$} & $P$ value & \multicolumn{2}{|c|}{$\begin{array}{l}\text { Bis-glycinate } \\
\text { chelate } \\
n=45\end{array}$} & \multicolumn{2}{|c|}{$\begin{array}{l}\text { Ferrous } \\
\text { sulfate } \\
n=44\end{array}$} & \multirow[t]{2}{*}{$P$ value } \\
\hline Hemoglobin concentration $\left(\mathrm{g} / \mathrm{l}^{\mathrm{a}}\right.$ & 141.6 & & 140 & & & 141.7 & & 140 & & & 141.7 & & 139. & & \\
\hline Standard deviation & 10.3 & & 7.6 & & $0.273^{b}$ & 8.2 & & 7.5 & & $0.175^{b}$ & 7.3 & & 6.9 & & $0.205^{b}$ \\
\hline Ferritin concentration $\left(\mu \mathrm{g} / \mathrm{l}^{\mathrm{a}}\right.$ & 8.7 & & 8.9 & & & 29.6 & & 28.9 & & & 31.0 & & 25.2 & & \\
\hline Standard deviation & 2.1 & & 2.1 & & $0.548^{\mathrm{b}}$ & 15.1 & & 13.1 & & $0.728^{b}$ & 18.7 & & 12.5 & & $0.090^{b}$ \\
\hline \multicolumn{16}{|l|}{ Iron nutritional status ${ }^{c}$} \\
\hline Low iron stores & 101 & 100 & 99 & 100 & & 9 & 10.5 & 6 & 6.7 & & 5 & 11.1 & 4 & 9.1 & \\
\hline Normal & 0 & 0.0 & 0 & 0.0 & - & 77 & 89.5 & 84 & 93.3 & $0.367^{d}$ & 40 & 88.9 & 40 & 90.9 & $0.752^{d}$ \\
\hline
\end{tabular}

${ }^{\mathrm{a}}$ Mean and standard deviation.

bStudent's $t$ test.

'Low iron stores $=$ Serum ferritin $<12 \mu \mathrm{g} / \mathrm{l}$

${ }^{\mathrm{d}}$ Pearson's $X^{2}$ test.

Effects on ferritin and hemoglobin concentration and on the risk of having iron deficiency

Multivariate analysis on the effect of supplementation on ferritin concentration after adjusting by age at the time of each biochemical determination and by sex showed the following: 1: Compared to baseline ferritin concentration, the children had a change of $20.16 \mu \mathrm{g} / \mathrm{l}$ one week postsupplementation and a change of $16.43 \mu \mathrm{g} / \mathrm{l} 6$ months after supplementation. 2: The effect was statistically different between iron compounds only at 6 months after supplementation. The group that received bis-glycinate chelate iron showed $6.04 \mu \mathrm{g} / \mathrm{l}$ higher ferritin concentration in comparison to the group with ferrous sulfate supplementation, $p=0.028$ (Table 3, Figure 2). The adjusted ferritin concentration one week post-supplementation, based on the model shown in Table 3, was estimated to be $28.9 \mu \mathrm{g} / \mathrm{l}$ (95\% CI: 26.6 - 31.2) and 6 months after supplementation of $25.2 \mu \mathrm{g} / \mathrm{l}(95 \% \mathrm{CI}: 21.9-28.5)$ in the group that received ferrous sulfate, and of $29.6 \mu \mathrm{g} / \mathrm{l}$ (95\% CI: 27.3 - 32.0) and $31.1 \mu \mathrm{g} / \mathrm{l}$ (95\% CI: 27.8 - 34.3), respectively, in the group that received bis-glycinate chelate (Figure 2). No significant effect was observed in Hb concentration (Table 4).

There were no differences between the odds of having low iron storages either in the group with iron bis-glycinate chelate versus the group that received ferrous sulfate, OR 1.40 (CI 95\%, $0.58-3.42$ ) either at 6 months postsupplementation versus one week post-supplementation, OR 1.40 (CI 95\%, 0.56 - 3.49), after adjustment for age, sex, ferritin, and hemoglobin concentration at baseline (Table 5).

\section{Discussion}

Our results showed that 90 days of supplementation with $30 \mathrm{mg} /$ day of elemental iron as either ferrous sulfate or iron bis-glycinate chelate had a positive effect on raising ferritin concentration in school-age children with

Table 3 Effects on mean concentration of ferritin according to iron compound and time of evaluation

\begin{tabular}{|c|c|c|c|}
\hline Supplement and time of evaluation & Change in mean of ferritin $(\mu \mathrm{g} / \mathrm{l})$ & $95 \% \mathrm{Cl}$ & $P$ value \\
\hline \multicolumn{4}{|l|}{ Supplement } \\
\hline Ferrous sulfate & Ref. & & \\
\hline Bis-glycinate chelate & -0.18 & $-3.26-2.91$ & 0.909 \\
\hline \multicolumn{4}{|l|}{ Time of evaluation } \\
\hline Baseline & Ref. & & \\
\hline One week post-supplementation & 20.16 & $17.11-23.22$ & 0.001 \\
\hline 6 months after supplementation & 16.43 & $12.57-20.28$ & 0.001 \\
\hline \multicolumn{4}{|c|}{ Additional increment in the group supplemented with Bis-glycinate chelate ${ }^{a}$} \\
\hline At baseline & Ref. & & \\
\hline One week post-supplementation & 0.87 & $-3.45-5.19$ & 0.694 \\
\hline 6 months after supplementation & 6.04 & $0.64-11.43$ & 0.028 \\
\hline
\end{tabular}

Mixed-effects linear regression model with random intercept, adjusted by age and sex. Number of observations: 465 , number of groups: 200 , observations per group: $2.3(1-3)$.

Ref. = Reference value.

anteraction between study stage and iron compound (bis-glycinate chelate vs. ferrous sulfate by time of evaluation). 


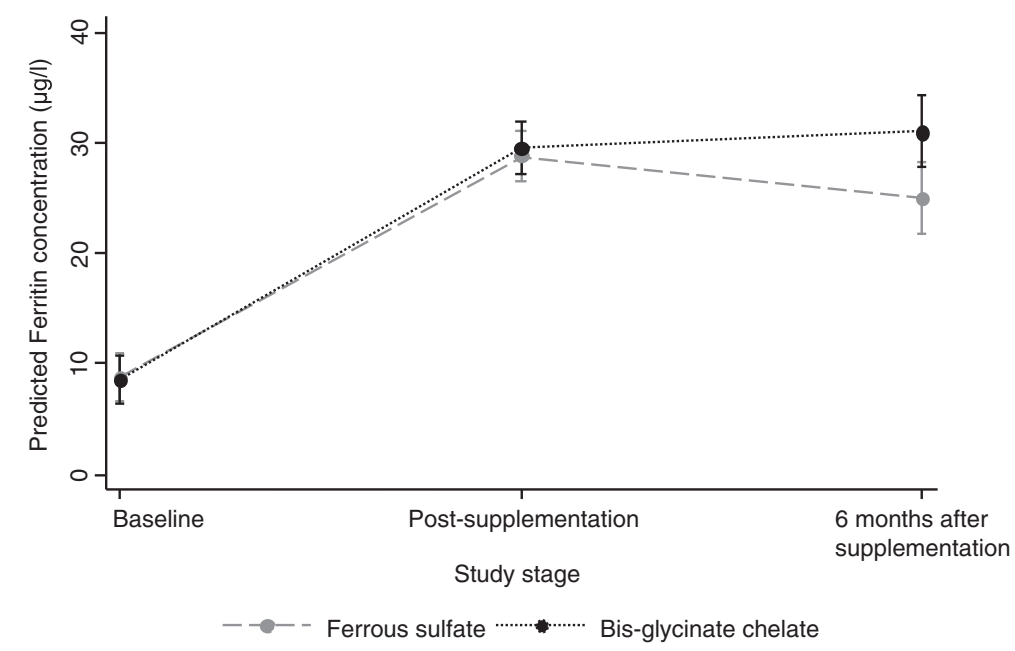

Figure 2 Predicted ferritin concentration $(\boldsymbol{\mu g} / \mathrm{l})$ by iron compound and time of evaluation. Results are based on the model shown in Table 3.

low iron stores. This effect was seen one week postsupplementation and was still present 6 months after supplementation. Furthermore, the bis-glycinate chelate compound was more efficient for maintaining higher ferritin concentration 6 moths after supplementation than ferrous sulfate. Persistence of the observed effect for this long period after supplementation may be explained by the effect of a diet that may provide enough bioavailable iron to maintain iron status once the initial deficit was overcome. Actually, the effect of iron bis-glycinate chelate may be larger where individuals consume a typical Mexican diet (as do families with low incomes, such as the ones included in this study), which includes phytic acid from cereals (i.e., maize) and legumes (i.e., beans). This compound binds iron, reducing its bioavailability for intestinal absorption.

In a longitudinal study about iron deficiency due to consumption of low bioavailable iron diet in Africa by schoolchildren with normal iron status after a fortification intervention, after 15 months the authors found a mean change in total body iron stores of $-142 \mathrm{mg}$, and estimated a $2 \%$ mean iron absorption of dietary iron.
Hemoglobin decreased by $12 \mathrm{~g} / \mathrm{l}$, and $75 \%$ of the cohort had deficit in tissue iron. The authors concluded that low iron bioavailability from a legume- and cereal-based diet is a cause of iron deficiency anemia in children in rural Africa [32]. In our study, there were no differences in the odds of having low iron storages between the two iron compounds at either evaluation period. This could mean that the higher ferritin concentration at 6 months post-supplementation in the bis-glycinate chelate group versus ferrous sulfate group had no clinical implication.

Our findings concurred with other studies carried out on pregnant women, adolescents, school-age children, and preschool children in which both ferrous sulfate and iron bis-glycinate chelate were found to be equally effective [20,33]; however, in those studies, the effects 6 months post-supplementation had not been evaluated. Results of a systematic review and meta-analysis on iron supplementation on children, that included 32 studies including 7,089 children aged 5-12 years; 31 of these studies were conducted in lower- or middle-income countries [9] and showed that iron supplementation improves hematologic and non-hematologic outcomes. Iron supplementation

Table 4 Effects on mean concentration of hemoglobin $(\mathrm{g} / \mathrm{l})$ according to iron compound and time of evaluation

\begin{tabular}{|c|c|c|c|}
\hline Supplement and time of evaluation & Change in mean $\mathrm{Hb}$ & $95 \% \mathrm{Cl}$ & $P$ value \\
\hline \multicolumn{4}{|l|}{ Supplement } \\
\hline Ferrous sulfate & Reference & & \\
\hline Bis-glycinate chelate & 1.71 & $-0.20-3.63$ & 0.080 \\
\hline \multicolumn{4}{|l|}{ Time of evaluation } \\
\hline Baseline & Reference & & \\
\hline One week post-supplementation & -0.11 & $-1.36-1.13$ & 0.859 \\
\hline 6 months after supplementation & -0.46 & $-2.08-1.16$ & 0.578 \\
\hline
\end{tabular}


Table 5 Association between iron compound at time of evaluation and low iron storages

\begin{tabular}{llll}
\hline Supplement and time of evaluation & OR & $\mathbf{9 5 \%} \mathrm{Cl}$ & $\boldsymbol{P}$ value \\
\hline $\begin{array}{l}\text { Supplement } \\
\quad \text { Ferrous sulfate }\end{array}$ & Ref. & & \\
$\quad$ Bis-glycinate chelate & 1.40 & $0.58-3.42$ & 0.452 \\
$\begin{array}{l}\text { Time of Evaluation } \\
\quad \text { One week post-supplementation }\end{array}$ & Ref. & & \\
6 months after supplementation & 1.40 & $0.56-3.49$ & 0.465 \\
\hline
\end{tabular}

Ref. $=$ Reference value.

Mixed effects logistic regression model with random intercept, adjusted by sex, age; ferritin and hemoglobin concentration at baseline. Number of observations: 265 , number of groups: 180 , observations per group: 1.5 (1-2).

decreased the prevalence of anemia by about $50 \%$ and reduced the prevalence of iron deficiency by $79 \%$; there was also evidence of a benefit on cognitive performance in children with anemia at baseline [9]. The increase in hemoglobin or ferritin concentrations is related to iron status at baseline, dose of iron, and length of time of supplementation $[3,34,35]$. However, most studies have focused on treating anemia more than on treating the iron deficiency to prevent iron deficiency anemia.

In a supplementation study carried out in Brazil that compared administration of ferrous sulfate $(40 \mathrm{mg}$ of iron per week) versus iron bis-glycinate chelate $(3.8 \mathrm{mg}$ per week as bis-glycinate chelate-enriched cookies) for 8 weeks on schoolchildren with anemia, the authors reported a significant increase in $\mathrm{Hb}$ concentration but no significant difference in the inter-group comparison. No effect was observed on serum ferritin for either intervention, but children with depleted iron stores (ferritin $<15 \mathrm{ng} / \mathrm{mL}$ ) at the beginning of the intervention showed increased serum ferritin concentration, although no difference between treatments was observed [33].

Ribeiro and Sigulem supplemented anemic children between 6 and 36 months with $5 \mathrm{mg} / \mathrm{kg} / \mathrm{d}$ of iron as bisglycinate chelate [36] and found a significant increase in the $\mathrm{Hb}$ concentration; however, ferritin concentration was not measured. Pineda and Ashmead supplemented children with anemia and malnutrition between 6 to 36 months of age with ferrous sulfate versus iron bisglycinate chelate offering $5 \mathrm{mg} / \mathrm{kg} / \mathrm{d}$ for 28 days. This study showed a significant increase in $\mathrm{Hb}$ and ferritin concentration in both supplemented groups. The difference in $\mathrm{Hb}$ concentration between the two groups postintervention was not statistically significant; however, the difference in the serum ferritin concentration was significantly higher in the group that received iron bisglycinate chelate [37]. In summary, these studies show a positive effect of supplementation with ferrous sulfate and of supplementation or food fortification with ferrous bis-glycinate chelate on treating anemia, but we found no published study that focused on preventing iron deficiency anemia in schoolchildren population that included the bis-glycinate chelate iron compound.

As mentioned, iron bis-glycinate chelate has been used for food enrichment and for supplementation. Due to its chemical structure (consisting of a covalently bounded iron molecule to an organic ligand, in this case glycine), this form of iron can be partially resistant to the action of enzymes and to the binding action of substances naturally present in food such as metals, dietary fiber, phytates, and phenols, with which the iron can form insoluble compounds. In addition, because of the amino acid bonding, there is less direct exposure of iron to the gastrointestinal mucosa cells; this can reduce local toxicity and side effects attributable to iron compounds present in the intestinal lumen, like abdominal pain $[18,19,33,37,38]$. In various supplementation studies, correlations have been noted between the doses of iron given and/or the chemical formula used and side effects. The most common side effects associated with iron supplementation affect the gastrointestinal tract, manifesting as constipation, nausea, diarrhea, and vomiting [1,3,36,38].

Coplin et al. compared the tolerability of ferrous sulfate and iron bis-glycinate chelate in a study. They found that both ferrous sulfate and iron bis-glycinate chelate had equivalent therapeutic efficiency at a similar dosage (50 $\mathrm{mg})$, but the side effects were greater (37\% vs. $21 \%$ ) in the group that received ferrous sulfate [20]. Gastrointestinal complaints and symptoms as constipation, nausea, vomiting, and diarrhea have been observed commonly in women consuming high doses of supplemental iron. The frequency and intensity of these complains are related to the amount of elemental iron released in the stomach $[1,39]$. In malaria areas, additional iron may exacerbate malaria infection. For theses reasons, iron supplementation programs should be supervised and planned according to target the population [1].

In a systematic review, Low et al. evaluated the benefits and safety of daily iron supplementation in school-aged children. There was no difference in the frequency of children with gastrointestinal upset, constipation, vomiting, or diarrhea between children who received iron supplementation and children in the placebo group. The authors concluded that iron supplements appeared to be well tolerated, but the safety dates were limited: only 6 of 32 studies reported safety outcomes [9]. In our study, there were few gastrointestinal side effects with either treatment, so there was no need to suspend supplementation. Moreover, there were no differences in the observation of gastrointestinal side effects between the two supplementation groups. This lack of significant side effects may have been due to the low dose of iron given $(30 \mathrm{mg} / \mathrm{d})$.

We recognize some caveats of our study. In terms of design, a more comprehensive description of iron status 
in the body would include other indicators of iron status, such as serum transferrin, serum transferring receptors, and total serum iron. Likewise, indicators of infection as $C$ reactive protein and $\alpha 1$-glycoprotein have been evaluated in some studies on iron supplementation. However, serum ferritin has been considered a good indicator of iron storage and is useful in evaluating interventions response at a population level [2].

While serum concentrations of this protein can be increased during inflammatory and infectious processes as well as in response to trauma, children participating in our study received anti-helminthic prophylaxis at the beginning of the study, and the blood sample was obtained only if the children did not have a cold, fever, or any other common symptom of infection, so we consider that the use of serum ferritin in this study was a good indicator of iron storage as well as a good indicator of intervention response at the population level, as has been suggested [5]. In terms of implementation, the main constraint of our study was related to the high attrition rate to effect evaluation at 6 months after supplementation. However, the only difference between participants who completed the study and the ones missing data during follow-up was age, and the results of our multivariate analyses were adjusted by age as soon as each evaluation of iron status was done. Therefore, we do not think that this attrition reflected a selection bias that could substantially bias our results.

\section{Conclusions}

The results of our study showed that a low iron dose of $30 \mathrm{mg} /$ day for 90 days with either ferrous sulfate or iron bis-glycinate chelate significantly increased serum ferritin concentration in schoolchildren with low iron stores but no anemia and had negligible side effects. The effect on increased iron status was sustained up to 6 months after supplementation, rendering both treatments as safe and effective. These results support the preventive effectiveness of this low-dose iron intervention to increase serum ferritin, which will help prevent iron deficiency anemia and may be relevant where iron deficiency is a public health concern and where a preventive daily low dosage of iron supplementation can be used to help the school-age population maintain an adequate nutritional iron status.

We recognize upfront, however, that iron supplementation is no substitute for a balanced diet and that in areas where parasitic infections are prevalent, these should be treated as part of a comprehensive approach to improve iron status. Furthermore, where malaria is endemic, we would caution against extended use of iron supplementation, even in small doses, until safety studies have been conducted. In these areas, the World Health Organization recommends to first treat the infection, and then to provide iron supplementation. In summary, while our results support that low daily doses of ferrous sulfate or bis-glycinate chelate iron can be utilized to prevent iron deficiency anemia in schoolchildren with iron deficiency, prevention and control of anemia are complex and, depending on the setting, may require the implementation of a comprehensive set of control measures [40].

\section{Competing interests}

The authors declare that they have no competing interests.

\section{Authors' contributions}

XD designed the study, analyzed data, and drafted the manuscript. HM critically revised the manuscript for important intellectual content and participated in interpretation of results. JV designed the study and managed the data base. RM coordinated the statistical analyses and participated in the interpretation of results. SF participated in the study design and statistical analyses. SM participated in the study design and results interpretation. EM was in charge of lab analyses and participated in the interpretation of results. FN, VR, and AS conducted the data collection, supplementation and collaborated in the interpretation of results. All authors read and approved the final manuscript.

\section{Acknowledgments}

This research was funded by the Mexican National Council for Science and Technology-CONACYT, Salud-C01 No. 69720, and the Coordination of Research in Health of the Mexican Institute of Social Security, register No. FIS/IMS/PROT/020.

\section{Author details}

${ }^{1}$ Instituto Mexicano del Seguro Social, Av. Cuauhtemoc No. 330, CP 06725 México, DF, México. ²RAND Corporation, Santa Monica, California 90407, USA. ${ }^{3}$ Hospital Infantil de México Federico Gómez, Dr. Marquez No. 162, CP 06720 México, DF, México. ${ }^{4}$ Instituto Nacional de Salud Pública, Universidad No. 658, CP 62100 Cuernavaca, Morelos, Mexico. ${ }^{5}$ Vanderbilt University Medical Center, Nashville, TN, USA.

Received: 18 February 2014 Accepted: 3 July 2014

Published: 15 July 2014

\section{References}

1. De-Regil LM, Jefferds ME, Sylvetsky AC, Dowswell T: Intermittent iron supplementation for improving nutrition and development in children under 12 years of age (Review). Cochrane Database Syst Rev 2011, 12: CD009085. doi: 10.1002/14651858.CD009085.pub2.

2. World Health Organization/Centers for Disease Control and Prevention: Assessing the iron status of populations: including literature reviews: report of a Joint World Health Organization/Centers for Disease Control and Prevention Technical Consultation on the Assessment of Iron Status at the Population Level, Geneva, Switzerland, 6-8 April 2004. Geneva: by WHO/CDC; 2007.

3. Balarajan Y, Ramakrishnan U, Özaltin E, Shankar AH, Subramanian SV: Anaemia in low-income and middle-income countries. Lancet 2011, 378:2123-2135.

4. Beard JL: Iron requirements in adolescent females. J Nutr 2000, 130:440S-442S.

5. Worwood M: Indicators of the iron status of populations: ferritin. In Assessing the Iron Status of Populations: Report of a Joint World Health Organization/Centers for Disease Control and Prevention Technical Consultation on the Assessment of Iron Status at the Population Level. 2nd edition. Edited by WHO CDC. Geneva: World Health Organization; 2007:35-74.

6. Grantham-McGregor S, Ani C: A review of studies on the effect of iron deficiency on cognitive development in children. J Nutr 2001, 131(2 Suppl):649S-668S.

7. Lozoff B, Jimenez E, Hagen J, Mollen E, Wolf AW: Poorer behavioral and developmental outcome more than 10 years after treatment for iron deficiency in infancy. Pediatrics 2000, 105:e51. 
8. United Nations Children's Fund, United Nations University, World Health Organization: Iron deficiency anaemia. Geneva: World Health Organization: Assessment, prevention and control, a guide for programme managers; 2001.

9. Low M, Farrell A, Biggs BA, Pasricha SR: Effects of daily iron supplementation in primary-school-aged children: systematic review and meta-analysis of randomized controlled trials. CMAJ 2013, 185(17):E791-E802.

10. Morales-Ruán MC, Villalpando S, García-Guerra A, Shamah-Levy T, Robledo-Perez R, Avila-Arcos MA, Rivera JA: Iron, zinc, cooper and magnesium nutritional status in Mexican children aged 1 to 11 years. Salud Publica Mex 2012, 54:125-134.

11. De la Cruz-Gongora V, Gaona B, Villalpando S, Shama-Levy T, Robledo R: Anemia and iron, zinc, cooper and magnesium deficiency in Mexican adolescents: National Health and Nutrition Survey 2006. Salud Publica Mex 2012, 54:135-145.

12. Gutierrez JP, Rivera-Dommarco J, Shamah-Levy T, Villalpando-Hernandez S, Franco A, Cuevas-Nasu L: Encuesta Nacional de Salud y Nutrición 2012. Resultados Nacionales. Cuernavaca, Mor., México: Instituto Nacional de Salud Pública; 2012

13. Panel on micronutrients, Subcommittees on Upper Reference Levels of Nutrients and of Interpretation and Uses of Dietary Reference Intakes, Standing Committee on the Scientific Evaluation of Dietary Reference Intakes, Food and Nutrition Board, Institute of Medicine: Dietary Reference Intakes for Vitamin A, Vitamin K, Arsenic, Boron, Chromium, Copper, lodine, Iron, Manganese, Molybdenum, Nickel, Silicon, Vanadium, and Zinc. Washington, D.C: National Academy of Sciences; 2001.

14. Sungthong R, Mo-Suwan L, Chongsuvivatwong V, Geater AF: Once weekly is superior to daily iron supplementation on height gain but not on hematological improvement among schoolchildren in Thailand. J Nutr 2002, 132:418-422.

15. Zlotkin S, Arthur P, Antwi KY, Yeung G: Randomized, controlled trial of single versus 3-times-daily ferrous sulfate drops for treatment of anemia. Pediatrics 2001, 108:613-618.

16. Bovell-Benjamin AC, Viteri FE, Allen LH: Iron absorption from ferrous bisglycinate and ferric trisglycinate in whole maize is regulated by iron status. Am J Clin Nutr 2007, 71:1563-1569.

17. Fox TE, Eagles J, Fairweather-Tait SJ: Bioavailability of iron glycine as a fortificant in infant foods. Am J Clin Nutr 1998, 67:664-668.

18. Mazariegos DI, Pizarro F, Olivares M, Nunez MT, Arredondo M: The mechanisms for regulating absorption of Fe bis-glycine chelate and Fe-ascorbate in CaCo-2 cells are similar. J Nutr 2004, 134:395-398.

19. Pizarro F, Olivares M, Hertrampf E, Mazariegos DI, Arredondo M, Letelier A, Gidi V: Iron bis-glycine chelate competes for the nonheme-iron absorption pathway. Am J Clin Nutr 2002, 76:577-581.

20. Coplin M, Schuette S, Leichtmann G, Lashner B: Tolerability of iron: a comparison of bis-glycino iron II and ferrous sulphate. Clin Ther 1991, 13(5):606-612

21. Giorgini E, Fisberg M, De Paula RA, Ferreira AM, Valle J, Braga JA: The use of sweet rolls fortified with iron bis-glycinate chelate in the prevention of iron deficiency anemia in preschool children. Arch Latinoam Nutr 2001, 51(1 Suppl 1):48-53.

22. lost C, Name JJ, Jeppsen RB, Ashmead HD: Repleting hemoglobin in iron deficiency anemia in young children through liquid milk fortification with bioavailable iron amino acid chelate. J Am Coll Nutr 1998, 17:187-194.

23. Olivares M, Pizarro F: Bioavailability of iron bis-glycinate chelate in water. Arch Latinoam Nutr 2001, 51(Suppl 1):22-25.

24. Blackwelder W: Proving the null hypothesis in Clinical Trials. Contro/ Clin Trials 1982, 3:345-353

25. Cohen JH, Haas JD: Hemoglobin correction factors for estimating the prevalence of iron deficiency anemia in pregnant women residing at high altitudes in Bolivia. Rev Panam Salud Publica 1999, 6(6):395-399.

26. Lohman TG, Roche AF, Martorell R: Anthropometric Standardization Reference Manual. Human Kinetics Books. Champaigne, 111; 1988.

27. Cole TJ, Bellizzi MC, Flegal KM, Dietz WH: Establishing a standard definition for child overweight and obesity worldwide: international survey. BMJ 2000, 320:1240-1243.

28. de Onis M, Onyango AW, Borghi E, Siyam A, Nishida C, Siekmann J: Development of a WHO growth reference for school-aged children and adolescents. Bull World Health Organ 2007, 85:660-667.

29. Muñoz M, Roldan JA, Ledesma JA, Mendoza E, Chaves A, Perez-Gil F, Hernandez SL, Chaparro A: Tablas de Valor Nutritivo de los Alimentos de Mayor Consumo en México. Mexico, D.F: Pax de Mexico; 1996.
30. Perez Lizaur AB, Palacios Gonzales B, Castro Becerra A: Sistema Mexicano de Alimentos Equivalentes. 3rd edition. Mexico, D.F: Cuadernos de Nutrición; 2008.

31. Twisk JWR: Analysis of experimental studies. In Applied Longitudinal Data Analysis for Epidemiology: a practical guide. Cambridge, UK: Cambridge University Press; 2004:179-202.

32. Zimmermann M, Chaouki N, Hurrell RF: Iron deficiency due to consumption of a habitual diet low bioavailable iron: a longitudinal cohort study in Moroccan children. Am J Clin Nutr 2005, 81:115-121.

33. Santos M, Nogueira N, Silva DA: Effectiveness of different iron supplementation strategies on hemoglobin and ferritin levels among schoolchildren in Teresina, Piauí State, Brazil. Cad Saude Publica 2007. 23(7):1547-1552

34. Lönnerdal B, Kelleher SL: Iron metabolism in infants and children. Food Nutr Bull 2007, 28:S494-S499.

35. Zimmermann M, Biebinger R, Egli I, Zeder C, Hurrell R: Iron deficiency up-regulates iron absorption from ferrous sulphate but not ferric pyrophosphate and consequently food fortification with ferrous sulphate has relatively greater efficacy in iron-deficient individual. British J Nutr 2011, 105:1245-1250.

36. Ribeiro L, Sigulem DM: Tratamento da anemia ferropriva com ferro quelato glicinato e crescimento de crianças na primeira infância. Rev de Nutriçao 2008, 21:483-490

37. Pineda $\mathrm{O}$, Ashmead $\mathrm{H}$ : Effectiveness of treatment of iron-deficiency anemia in infants and young children with ferrous bis-glycinate chelate. Nutrition 2001, 17:381-384.

38. Peña-Rosas JP, De-Regil LM, Dowswell T, Viteri FE: Daily oral iron supplementation during pregnancy. Cochrane Database Syst Rev 2012, CD004736. DOl: 10.1002/ 14651858.CD004736.pub4.

39. Peña-Rosas JP, Viteri FE: Effects and safety of preventive oral iron + folic acid supplementation for women during pregnancy. Cochrane Database Syst Rev 2009, CD004736. DOI: 10.1002/14651858.cd004736.pub3.

40. Righetti A, Koua A, Adiossa L, Glinz D, Hurrell R, N'Goran E, Niamké S, Wegmüller R, Utzinger J: Etiology of anemia among infants, school-aged children, and young non-pregnant women in different settings of South-Central Cote d'Ivoire. Am J Trop Med Hyg 2012, 87(3):425-434.

doi:10.1186/1475-2891-13-71

Cite this article as: Duque et al.: Effect of supplementation with ferrous sulfate or iron bis-glycinate chelate on ferritin concentration in Mexican schoolchildren: a randomized controlled trial. Nutrition Journal 2014 13:71.

\section{Submit your next manuscript to BioMed Central and take full advantage of:}

- Convenient online submission

- Thorough peer review

- No space constraints or color figure charges

- Immediate publication on acceptance

- Inclusion in PubMed, CAS, Scopus and Google Scholar

- Research which is freely available for redistribution 